\title{
Cryopreservation without vitrification suitable for large scale cryopreservation of orchid seeds
}

\author{
Emily Schofield, Edward P. Jones and Viswambharan Sarasan*
}

\begin{abstract}
Background: Orchids are under threat from human activities and climate change, with populations limited to small geographic hotspots. This makes them ideal candidates for ex situ conservation. Orchid seeds are desiccation tolerant, but often have poor longevity in seed banks and cryopreservation of orchid protocorms is complex and expensive. Therefore, simple methods for large-scale storage programs are essential to store orchid seeds of different life forms. Seeds of five species representing epiphytic, lithophytic and terrestrial orchids from the Central Highlands of Madagascar were studied to find a simple and effective system of cryopreservation. The use of a vitrification solution prior to cryopreservation to improve survival was investigated, as well as the use of symbiotic and asymbiotic germination media to maximise germination after cryopreservation. Using the filter paper packet method, dried seeds were stored in vapour phase above liquid nitrogen and recovered after thawing with both symbiotic and asymbiotic media.

Results: The study revealed that cryoprotection is not essential for the species in this study, which represented a range of lifeforms. Vitrification generally led to a decrease in germination post cryopreservation. The use of a symbiotic germination medium post cryopreservation was found to be successful in the species in which it was tested. However, the use of an asymbiotic medium was successful for all the species in this study.

Conclusions: Vitrification was not essential for the species in this study as the orchid seeds were already ultralow temperature and desiccation tolerant. However, further studies using more species are required to validate this approach. This may be an ecophysiological or genetic trait of these species. Therefore, this form of dry seed cryopreservation could form part of ex situ orchid seed conservation using a standard method. The methods developed here will store greater genetic diversity compared to what can be achieved with protocorms and are suitable for both asymbiotic and symbiotic recovery after cryopreservation. This will help reduce the time and cost of ex situ conservation, and help develop universal protocols for large genera, compared to custom protocols required for protocorm cryopreservation.
\end{abstract}

Keywords: Epiphyte, Ex situ conservation, Endemic, Madagascar, Lithophyte, Orchid seed, Terrestrial

\section{Background}

The Orchidaceae is probably the largest family of flowering plants with more than 27,000 species (Zotz 2013) and is the most diverse plant group (Swarts and Dixon 2009), with high levels of ecological specialisation for pollinators and mycorrhizal fungi (Bailarote et al. 2012). The Itremo region in the Central Highlands of Madagascar

*Correspondence: v.sarasan@kew.org

Natural Capital and Plant Health, Royal Botanic Gardens, Kew, Richmond TW9 3AE, UK is a micro-hotspot for orchids (Yokoya et al. 2015). The taxa we studied were from granite and quartz outcrops, and montane grassland. Seed banking is one of the cornerstones of ex situ biodiversity conservation. The majority of epiphytic orchids are desiccation tolerant, and can be stored at $-20{ }^{\circ} \mathrm{C}$ in seed banks (Seaton et al. 2010). According to Merritt et al. (2014) seed life span depends on seed traits, along with the biotic and abiotic components of their environment. Desiccation tolerance is common in most orchids, but longevity in storage using 
conventional seed banking is poor ( $\mathrm{Li}$ and Pritchard 2009). Therefore, cryopreservation offers a viable longterm seed storage option (Popova et al. 2016).

Seed and protocorm cryopreservation utilises a range of different available methods including: direct freezing, encapsulation-vitrification and droplet-freezing, each tested in several taxa (Sakai and Engelmann 2007; Sopalun et al. 2010; Jitsopakul et al. 2012; Hu et al. 2013; Galdiano et al. 2014; Teixeira da Silva et al. 2014; Popova et al. 2016). However, protocorms, a widely used propagule for cryopreservation, are prone to cryopreservation injury due to their cellular structure and high-water content. Our preliminary studies using protocorms of selected species yielded no successful recovery (unpublished data). Use of seeds reduces the intrinsic risk of intracellular damage due to ice crystal formation (Kulus and Zalewska 2014) owing to low water content of mature seeds (Jitsopakul et al. 2008). Thousands of seeds can be stored in a relatively small space with low maintenance requirements (Popova et al. 2003). There is also the added benefit of storing a wider genetic diversity compared to what can be achieved using protocorms. This can be achieved either by storage in liquid nitrogen at $-196{ }^{\circ} \mathrm{C}$ or in its vapour phase around $-150{ }^{\circ} \mathrm{C}$ (Vendrame et al. 2014). Therefore, we are exploring the feasibility of dry seed cryopreservation without the use of a cryoprotectant and comparing symbiotic and asymbiotic media for post-cryopreservation recovery.

\section{Methods}

The current study examines the viability of dry seed as propagules for the cryopreservation. To test this, three Angraecum species (A. protensum, A. rutenbergianum and $A$. sesquipedale) were cryopreserved with and without cryoprotectant. Vitrification using plant vitrification solution 2 (PVS2) was used in this study, due to its ability to remove and replace a large proportion of intracellular water from plant tissue (Kulus and Zalewska 2014). In addition, to test the use of symbiotic recovery after cryopreservation, Angraecum magdalenae and Benthamia cinnabarina were recovered using both asymbiotic and symbiotic methods. Popova et al. (2016) reviewed published seed cryopreservation to date and cryopreservation of both orchid and its fungal symbiont has been reported before as an experimental model (Batty et al. 2001; Teixeira da Silva et al. 2014). Merritt et al. (2014) proposed more advanced cryopreservation methods than currently available and simultaneous storage of seeds and fungal symbionts in a single system as potential area for future development. Our study takes the first step towards this by exploring possible simplification of the method of dry orchid seed cryopreservation. Therefore, our primary question concerns the development of a cost-effective and simple model to cryopreserve seeds from different life forms of orchids using dry seeds. Results will be discussed in the context of large scale ex situ programmes for threatened orchids from habitats where the threat to biodiversity is greater than anywhere else in the world.

\section{Plant species}

Five taxa were chosen for this study representing epiphytic, lithophytic and terrestrial life forms (Table 1). Lithophytic and terrestrial groups require niche habitats and are less abundant in Madagascar compared to epiphytic taxa. The genus Angraecum consists of 210 species, of which 128 are endemic to Madagascar (Cribb and Hermans 2009). The research permits from the Madagascar Forestry Authority and CITES (Convention of International Trade in Endangered Species of Wild Flora and

Table 1 Orchid taxa and orchid mycorrhizal fungi studied, their life form and habitat in the wild

\begin{tabular}{|c|c|c|}
\hline Orchid & Orchid life form & Habitat \\
\hline Angraecum magdalenae & Lithophyte & On or near quartz boulders \\
\hline Angraecum protensum & Lithophyte & Granite and quartz outcrops \\
\hline Angraecum sesquipedale & Epiphyte & $\begin{array}{l}\text { Sloping tree trunks in humid forest (collected from glasshouse at Royal } \\
\text { Botanic Gardens Kew) }\end{array}$ \\
\hline Angraecum rutenbergianum & Epiphyte & Tree trunks of evergreen humid forests \\
\hline Benthamia cinnabarina & Terrestrial & $\begin{array}{l}\text { Montane grassland in sandy soil at the borders of granite and quartz } \\
\text { boulders }\end{array}$ \\
\hline $\begin{array}{l}\text { OTU (operational taxonomic unit) } \\
\text { name of the mycorrhizal fungus } \\
\text { (OMF) }\end{array}$ & Orchid life form of OMF partner & Habitat \\
\hline Tul1 & $\begin{array}{l}\text { Angraecum magdalenae } \\
\text { (Lithophyte) }\end{array}$ & Montane grassland in a crack in granite \\
\hline Tul2 & $\begin{array}{l}\text { Benthamia cinnabarina } \\
\text { (Terrestrial) }\end{array}$ & $\begin{array}{l}\text { Montane grassland in sandy soil at the borders of granite and quartz } \\
\text { boulders }\end{array}$ \\
\hline
\end{tabular}


Fauna) permit for collecting the seeds are included as Additional file 1. We selected two lithophytic Angraecum species; $A$. protensum and $A$. magdalenae from quartz and granite outcrops, both of which grow on boulders or large rocks. Two epiphytic Angraecum species were collected, A. rutenbergianum from the Central Highlands of Madagascar (CHM) gallery forest and A. sesquipedale from a glasshouse collection in the Royal Botanic Gardens, Kew to investigate whether the observed desiccation tolerance traits were genetic or ecophysiological. The terrestrial species tested was Benthamia cinnabarina, a montane grassland species found in sandy soil at the borders of granite and quartz boulders (Table 1). Due to restrictions on collecting, a maximum of three capsules were collected from the wild, however, in many cases only one or two capsules were available for collecting at each site. The seeds used for each species were a mixture of seeds from at least 3 capsules. They were mixed before being stored at $4{ }^{\circ} \mathrm{C}$.

\section{Orchid mycorrhizal fungi (OMF)}

The different OMF (orchid mycorrhizal fungi) isolates (Tul denotes Tulasnella) Tul1 and Tul2 (Table 1) were collected from the Central Highlands of Madagascar. The isolates used in this study were collected, isolated and cultured as described by Yokoya et al. (2015) and isolates were selected from in vitro cultures stored at $18^{\circ} \mathrm{C}$.

\section{Seed sowing}

Freshly collected mature seeds were cleaned and dried over $\mathrm{LiCl}$ for 2 weeks and stored at $4{ }^{\circ} \mathrm{C}$ until used for the study (approximately 1 year). Lithium chloridemediated drying is a commonly used method (Galdiano et al. 2014). A pinch of seeds (ranging from 300 to 2000 seeds depending on the species) were transferred to hardened filter paper (Whatman, UK) and stapled. Due to the rare nature of the orchids and therefore limited seeds available, only one replicate per treatment was possible. Seed packets destined for direct sowing were surface sterilised in Magenta ${ }^{\mathrm{TM}}$ jars containing $50 \mathrm{ml}$ of $0.5 \%$ sodium dichloroisocyanurate for $1 \mathrm{~h}$. The other seeds were treated with or without vitrification solution. The vitrified seeds were then recovered and sterilised as described above. Once sterilised all seeds were washed in sterile water for $4 \mathrm{~min}$ and sown onto recovery medium 1 (RM1), Phytamax (Sigma, UK) with 3\% sucrose and $0.15 \%$ activated charcoal, and recovery medium 2 (RM2), Oat Meal Agar medium (Clements 1988). RM2 was used for both asymbiotic and symbiotic recovery. The symbiotic RM2 consists of either OMF isolates Tul1 and Tul2 and (Rafter et al. 2016) (Table 1). Tul1 (originated from a lithophyte) and Tul2 (originated from a terrestrial) were specifically selected as these fungi were isolated from the mature roots of Angraecum magdalenae and Benthamia cinnabarina respectively, two of the taxa studied here (Table 1). Yokoya et al. (2015) were unsuccessful to isolate OMF from roots of both A. protensum and A. sesquipedale roots, therefore, only asymbiotic (RM1) medium was used for these species. Packets were cut open and seeds spread onto both asymbiotic (RM1) and symbiotic media (RM2). Non-cryopreserved controls were treated with PVS2 and then sown as above.

\section{Cryopreservation \\ Effect of vitrification on recovery of seeds after cryopreservation}

Seeds, in seed packets as described above but without the sterilisation step, were treated directly in PVS2 for different times $(0,30,45$ and $60 \mathrm{~min})$, and then transferred into Nunc ${ }^{\mathrm{TM}}$ cryovials (Sigma-Aldrich, Gillingham, UK) and covered with PVS2. Seeds with 0 min treatment were not treated with PVS2. Lids were put on both sets of cryovials, with and without PVS2 and dipped into liquid nitrogen on multi-vial trays, then put directly in the vapour phase above Liquid Nitrogen (LN) $\left(-170 \pm 5{ }^{\circ} \mathrm{C}\right)$ in a D4000 Cryo Dewar (International Cryogenics, Indiana, USA) and stored for 1 week.

\section{Recovery}

Cryovials containing seeds were removed from the Dewar and put in a water bath at $38{ }^{\circ} \mathrm{C}$ for $2 \mathrm{~min}$. PVS2 solution was removed from the vial using Pasteur pipette and replaced with $1 \mathrm{ml}$ of $1.2 \mathrm{M}$ sucrose solution to completely cover the packet and then repeated twice. The 0 min PVS2 control vial was transferred directly into water bath for $2 \mathrm{~min}$ for thawing without sucrose solution. Seeds were sterilised after thawing, before sowing onto media as described above.

\section{PVS toxicity}

After the initial cryopreservation experiments Angraecum protensum seeds treated with plant vitrification solution 2 (PVS2) achieved very little germination. Therefore, the effect of vitrification was tested using Plant Vitrification Solutions PVS2 (30\% (v/v) glycerol (Merck, Hertfordshire, UK), 15\% (v/v) ethylene glycol (Sigma-Aldrich, Gillingham, UK), 15\% (v/v) Dimethyl sulfoxide (DMSO) (Sigma-Aldrich, Gillingham, UK) and $0.4 \mathrm{M}$ sucrose $1 / 2$ Murashige and Skoog solution ( $1 / 2$ MS) (Duchefa Biochemie, Haarlem, the Netherlands)) (Sakai et al. 1990) and PVS3 (50\% glycerol, 50\% sucrose (Sigma-Aldrich, Gillingham, UK)) (Nishizawa et al. 1993). A. protensum seeds were cryopreserved with either 30 or 60 min PVS2, PVS3 or no PVS. 


\section{Data analysis}

Germination was assessed 12 weeks after thawing as described by Yamazaki and Miyoshi (2006). The process of seed germination was divided into six categories according to the developmental stage of the embryos, adapted from Miyoshi and Mii (1995), as follows; Stage 0-cultured seed; Stage 1-imbibed seed; Stage 2-testa broken by emerging protocorm Stage 3-protocorm has emerged from the testa; Stage 4-protocorms with rhizoids; Stage 5-shoot primordium visible. Germination was determined to have occurred at stage 4 and 5 (protocorm and seedling stage). Assessments of germination were done under a stereo-microscope (Leica, Germany). Cryopreservation data was analysed using either an ANOVA or Two Sample T test in Microsoft Excel (Microsoft, Reading, UK). The effect of PVS2 and the recovery media used was investigated in cryopreserved and non-cryopreserved seeds.

\section{Results}

\section{Effect of vitrification solutions on recovery of seeds} after cryopreservation

In order to test the effect of vitrification in Angraecum, A. protensum was tested for PVS2 toxicity. Germination (protocorm and seedling stage combined) after PVS2 and PVS3 treatments was recorded to assess seed viability after vitrification and cryopreservation. The highest germination percentage after cryopreservation occurred when the seeds were not vitrified before cryopreservation (Fig. 1).

\section{Effect of vitrification on non-cryopreserved seeds}

PVS2 reduced the average seed germination of all the tested species apart from Angraecum magdalenae when recovered with recovery medium 1 (RM1) without undergoing cryopreservation (Fig. 2). However, when the mean germination of all the tested species combined was analysed using an ANOVA test there was no significant difference between the average germination of seeds treated with or without PVS2 $\left(\mathrm{F}_{2}=0.004, \mathrm{P}=0.99\right)$.

\section{Effect of vitrification on cryopreservation of seeds}

A similar pattern as that of the non-cryopreserved seed was found when seeds were treated with PVS2 and cryopreserved. The only species to have increased germination in response to cryopreservation following PVS2 treatment was $A$. magdalenae. A decrease in average germination was found for $A$. protensum, A. magdalenae and $A$. rutenbergianum (Fig. 2). There was also no significant difference in the mean germination across the four species when analysed using an ANOVA test $\left(\mathrm{F}_{10}=0.02\right.$, $\mathrm{P}=0.97$ ) (Fig. 3).

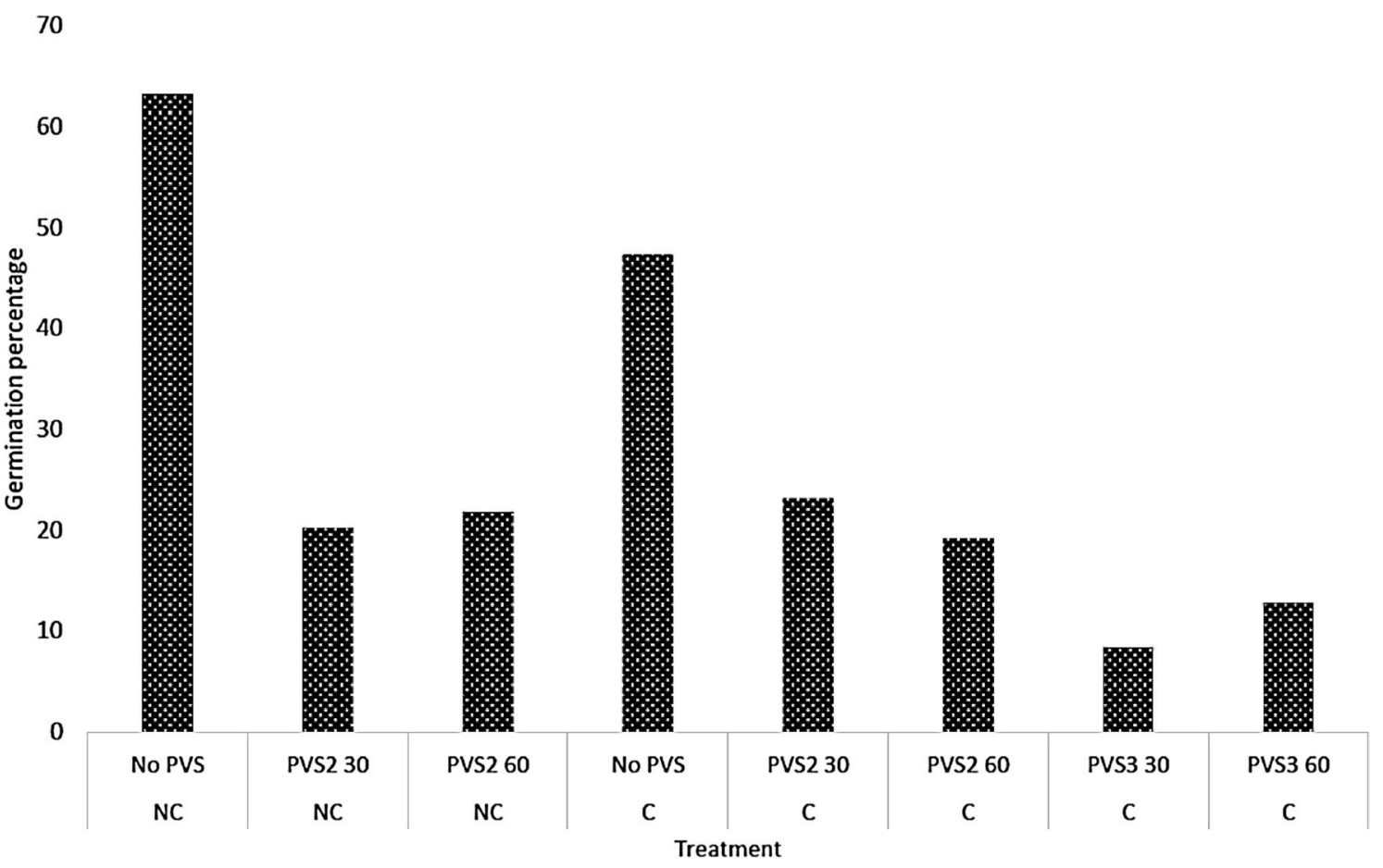

Fig. 1 The effect of pre-treatment of PVS2 and PVS3 (30 and $60 \mathrm{~min}$ ) on germination (protocorms and seedlings) of cryopreserved Angraecum protensum on recovery medium 1 (RM1) containing Phytamax nutrients. C cryopreserved, NC non-cryopreserved. Total viable seed tested $=10,535$ 


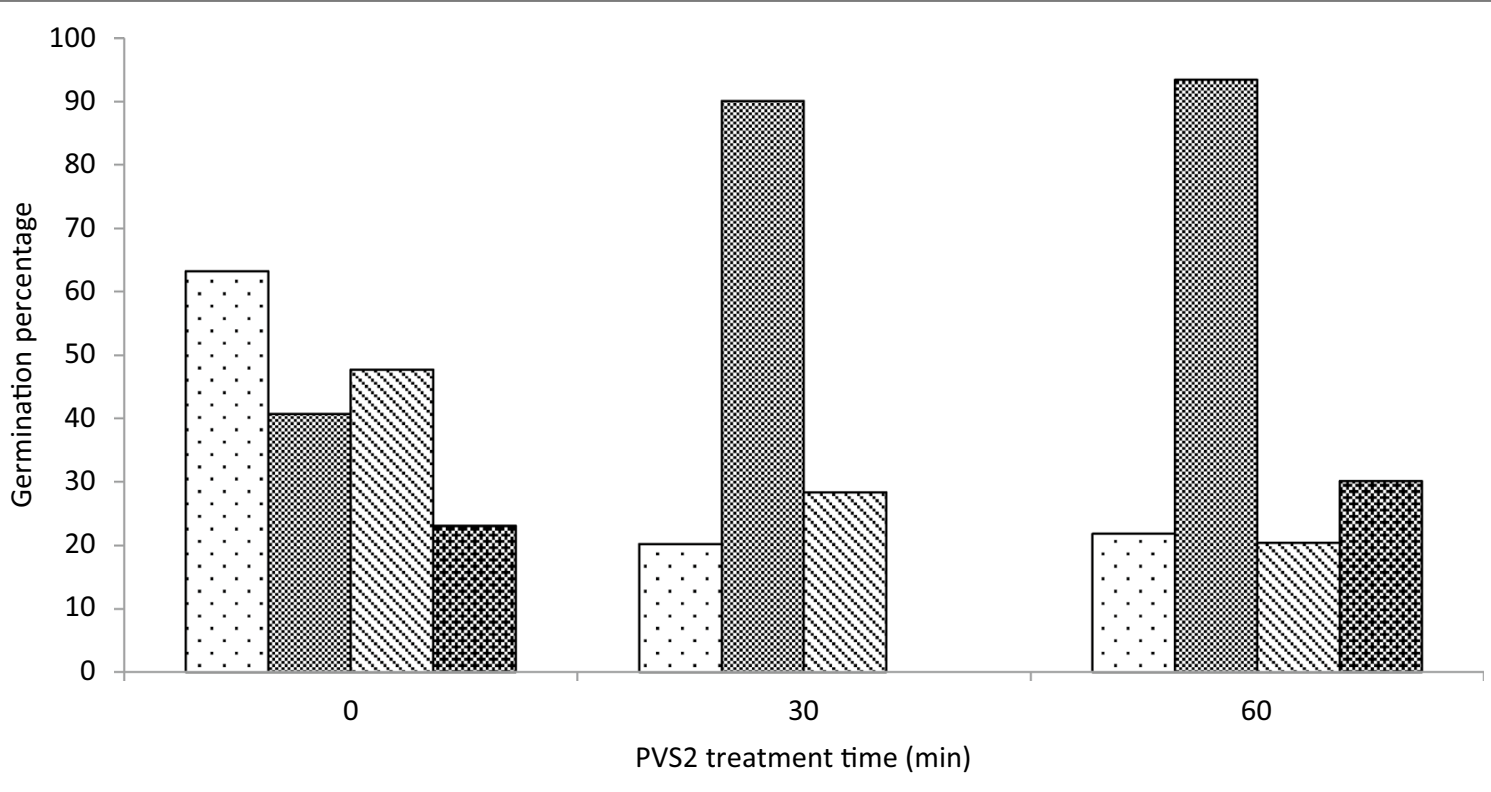

\section{$\square$ A. protensum $\mathrm{B}$ A. magdalenae $\mathrm{A}$ A. rutenbergianum $\mathrm{B}$. cinnabarina}

Fig. 2 Percentage of germination (protocorms and seedlings) of non-cryopreserved seeds of four species of orchids (Angraecum magdalenae, A. protensum, Benthamia cinnabarina and A. rutenbergianum) treated with PVS2 and recovered on recovery medium 1 (RM1) containing Phytamax nutrients. Total viable seed tested $=3084$

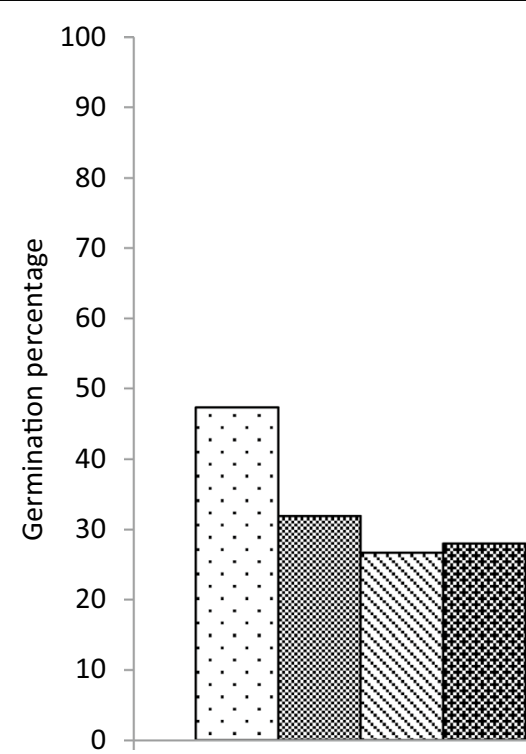

0

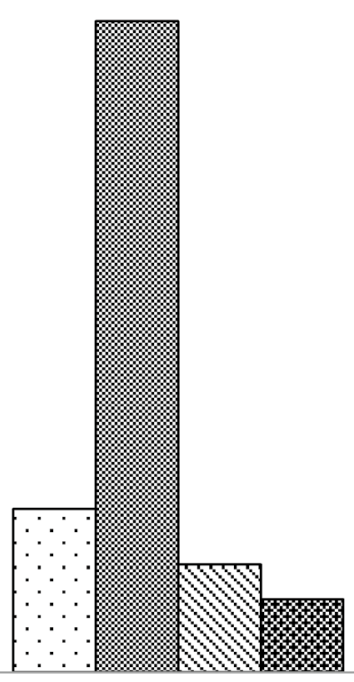

30

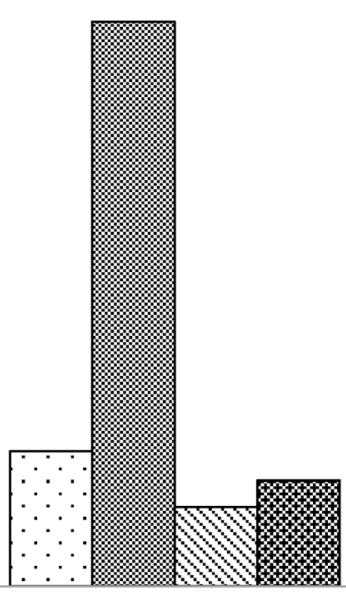

60

PVS2 treatment time (min)

\section{$\square$ A. protensum $\quad$ A. magdalenae $\$$ A. rutenbergianum}

Fig. 3 Germination (protocorms and seedlings) percentage of cryopreserved seeds of four species of orchids (Angraecum magdalenae, A. protensum, A. rutenbergianum and Benthamia cinnabarina) treated with PVS2 and recovered on recovery medium 1 containing Phytamax nutrients. Total viable seed $=3082$ 


\section{Traits of orchids from the same region}

Angraecum magdalenae and B. cinnabarina occur in the same area of the Central Highlands of Madagascar. Therefore, these species were compared to test whether a requirement for PVS2 vitrification before cryopreservation is an ecophysiological or species-specific effect.

\section{A. magdalenae}

The lithophytic $A$. magdalenae behaved in a similar way to the terrestrial $B$. cinnabarina. Cryopreservation did not significantly reduce germination, compared to non-cryopreserved controls with 30 min PVS2 $\left(\mathrm{X}_{1}=0.0002, \mathrm{P}=0.98\right)$. However, unlike B. cinnabarina, A. magdalenae benefitted from PVS2 treatment (Fig. 4a). Significantly more recovery was found after cryopreservation with 30 min PVS2 compared to no PVS2 treatment $\left(X_{1}=192.23, P=<0.01\right)$.

\section{B. cinnabarina}

Cryopreservation without vitrification was not harmful to seed recovery, with no significant difference in germination between the non-cryopreserved and cryopreserved treatments without PVS2 $\left(X_{1}=0.34, P=0.55\right)$, (Fig. 4b). Unlike A. magdalenae, PVS2 had no significant benefit to the recovery of cryopreserved $B$. cinnabarina seed, with no significant difference in recovery between 0 and 60 min PVS2 treatment $\left(X_{1}=0.48, P=0.48\right)$.

\section{Symbiotic vs. asymbiotic recovery}

Angraecum magdalenae and B. cinnabarina were recovered symbiotically and asymbiotically to understand the relative benefits of symbiotic recovery in two species with different lifeforms (Table 2).
Table 2 Germination (protocorms and seedlings) of Angraecum magdalenae and Benthamia cinnabarina after cryopreservation with the optimum PVS2 treatment for each species

\begin{tabular}{lll}
\hline Medium & A. magdalenae & B. cinnabarina \\
\hline Symbiotic (RM2+fungus) & 79.6 & 15.0 \\
Asymbiotic (RM1) & 92.5 & 23.2
\end{tabular}

RM2 tul1 was the symbiotic medium for $A$. magdalenae and RM2 tul2 for $B$. cinnabarina

\section{Benthamia cinnabarina}

The symbiotic medium RM2 tul2 produced the maximum germination after 60 min PVS2 and cryopreservation, although this was not significantly more than the asymbiotic RM1 medium $\left(\mathrm{X}_{1}=1.04, \mathrm{P}=0.31\right)$. Both asymbiotic RM1 and symbiotic RM2 tul2 were found to facilitate germination to seedling stage.

\section{Angraecum magdalenae}

No significant difference was found between recovery of cryopreserved seeds on the asymbiotic medium RM1 compared to the symbiotic medium RM2 tul1 ( $\mathrm{X}_{1}=0.38$, $\mathrm{P}=0.54)$. Pre-treatment with $30 \mathrm{~min}$ PVS2 with recovery medium RM2 tul1 led to $65 \%$ germination, but only $13 \%$ progression to seedling stage. This contrasts with asymbiotic germination using RM1, which facilitated $66 \%$ of the germinated seeds to progress to seedling stage. Using a symbiotic recovery medium led to a high percentage of seeds becoming stuck at protocorm stage which could not progress to full seedling stage. This did not occur when the seeds were recovered on RM1.

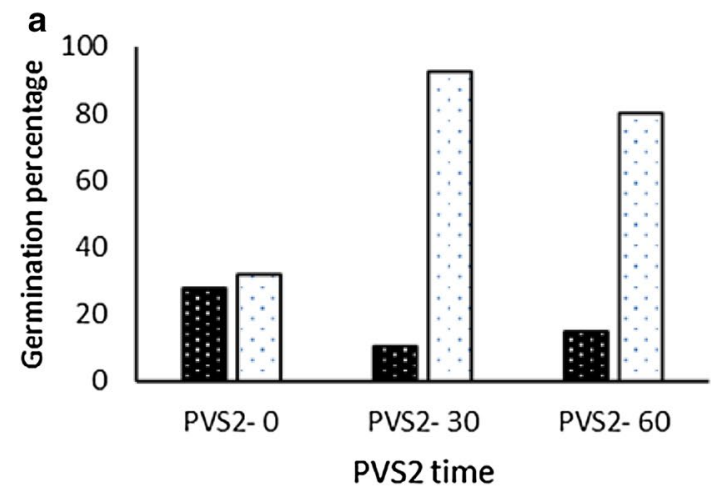

B. cinnabarina $\square$ A. magdalenae

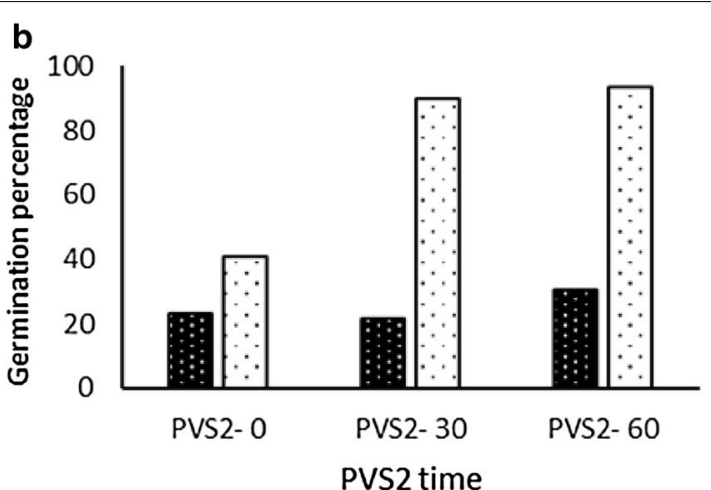

B. cinnabarina $\square$ A. magdalenae

Fig. 4 a Germination (protocorms and seedlings) percentage of B. cinnabarina and A. magdalenae cryopreserved with and without PVS2 treatment. Total seeds $=1969$. b The germination percentage (protocorm and seedling) of non-cryopreserved B. cinnabarina and A. magdalenae. All seeds were recovered on recovery medium 1 (RM1) containing Phytamax nutrients. Total viable seeds tested $=1908$ 


\section{Discussion}

\section{Need for vitrification before cryopreservation}

This study clearly demonstrates that for the tested orchid seeds of Angraecum spp. and B. cinnabarina vitrification is not critical. Although vitrification is considered essential for the cryopreservation of protocorm and shoot tissue, direct cryopreservation of seeds without vitrification has been reported in other taxa (Popova et al. 2016). As more than one lifeform were tested, the lack of requirement for vitrification is unlikely to be due to a species or lifeform specific factor. This is in contrast to a number of previous studies of other tropical and subtropical species (Nikishina et al. 2001; Yamazaki and Miyoshi 2006), that are not traditionally considered desiccation and ultra-low temperature-tolerant (Popova et al. 2016). Orchid seeds are generally classified as orthodox with very low water content. However, further studies are required to determine the molecular mechanisms that allow cryopreservation without vitrification.

Angraecum magdalenae was the only species tested that significantly benefitted from vitrification before cryopreservation. Pre-treatment with 30 min PVS2 promoted germination to $92 \%$ compared to only $40 \%$ without PVS2 treatment. Despite the impressive germination after cryopreservation with PVS2, this is an exception to the general trend observed in this study. Previous studies have also successfully recovered $A$. magdalenae without vitrification (Nikishina et al. 2001). Therefore, we argue that the percentage of seeds successfully recovered without the use of PVS2 would be satisfactory for the long term cryogenic storage of $A$. magdalenae. If a less than optimum germination percentage could be accepted, then the need for expensive and time consuming extensive pre-screening of each individual orchid species before cryopreservation would be avoided.

Benthamia cinnabarina is from the granite and quart outcrops in the Central Highlands of Madagascar, like $A$. protensum and $A$. magdalenae studied here. As a terrestrial species we expected that $B$. cinnabarina would be more likely to require cryoprotection compared to the lithophytic species studied. However, $B$. cinnabarina did not require vitrification, whereas the lithophytic $A$. magdalenae benefitted from 30 min PVS2 pre-treatment. The mechanism behind the need for vitrification might be due to ecophysiological factors, as the terrestrial B. cinnabarina is adapted to a low moisture environment. However, A. sesquipedale seeds collected from the glasshouse at Kew also demonstrated desiccation and ultralow temperature tolerance, being cryopreserved most successfully without vitrification. This suggests that this response may also have a genetic basis. By conducting larger trials in different species of Benthamia and Angraecum from a range of habitat types will shed light on the traits that are linked to seed tolerance of ultralow temperature.

A universal cryopreservation method has yet to be found that is suitable for the seeds of a range of orchid species (Popova et al. 2016). Therefore, the observation that vitrification is not critical for cryopreservation in the studied Angraecum and Benthamia species from Madagascar has significance to the conservation of other related species from the genera and beyond. This finding could contribute to further studies in 128 species of Angraecum and more than 35 species of Benthamia for quick screening and development of generalised cryopreservation protocols. Habitat destruction continues at an unprecedented pace in the Central Highlands of Madagascar, leading to habitat fragmentation (Ramiadantsoa et al. 2015), and driving many endemic orchids to the verge of extinction.

\section{Symbiotic recovery of seeds}

Asymbiotic recovery media is the current standard approach to recover cryopreserved orchid seeds. However, symbiotic germination of orchid seeds is more successful when reintroducing orchids into the wild (Johnson et al. 2007). Most mature orchids produce multiple seed pods each season, each containing thousands of seeds (Swarts and Dixon 2009). Therefore, 30-50\% recovery after cryopreservation would still be able to potentially produce hundreds or even thousands of plants for re-establishment of orchid populations in the wild. Cryopreservation without vitrification will help develop low-cost cryopreservation methods, as described by Li and Pritchard (2009).

Maximum A. magdalenae germination was achieved with asymbiotic recovery. Despite the tul 2 isolate being able to promote germination after cryopreservation, it was unable to promote germination to seedling stage. Phytamax was effective at germinating all the species in this study. It contains nitrogen in a form which is accessible to the plant, organic compounds and sucrose, all components required for the germination of many different orchid species (Dutra et al. 2008). The selected fungus used for symbiotic recovery in this study may have been unable to provide the appropriate nutrients or sugars to the germinating orchid seed. This highlights the vital importance of selecting the appropriate mycorrhizal fungus to promote germination to seedling stage, and the need for large scale screening of mycorrhizal fungal isolates to identify these for each cryopreserved orchid species.

Previous studies have either focussed on encapsulation of the seed and mycorrhizal fungus (Wood et al. 2000) or separate storage and recovery of the orchid and its symbiont (Sommerville et al. 2008; Ercole et al. 2013). These 
require initial investment into finding an appropriate mycorrhizal partner and optimisation of storage conditions for both the fungus and orchid. This is likely to be a secondary step and less suitable for orchid species that are under immediate threat, due to the time required for optimisation.

\section{Conclusions}

This study across many orchid species has found that PVS2 is not a requirement for ex situ storage of orchid seeds from the Central Highlands of Madagascar. Despite A. magdaleane benefitting from PVS2 pre-treatment before cryopreservation, sufficient germination after cryopreservation without vitrification was achieved for potential reintroduction to take place. This approach could be the basis of a large scale ex situ conservation strategy for orchids under immediate threat of extinction. Aiming for sufficient instead of optimum germination is a good initial step to protect critically endangered orchids. This can then be followed up with a more specific symbiotic storage method using a compatible mycorrhizal fungus to aid the production of seedlings suitable for long term reintroduction to the wild.

\section{Additional file}

Additional file 1. Raw data.

\begin{abstract}
Abbreviations
PVS2: plant vitrification solution 2; PVS3: plant vitrification solution 3; CITES: Convention on International Trade of Endangered Species of Wild Flora and Fauna; CHM: Central Highlands of Madagascar; OTU: operational taxonomic unit; OMF: orchid mycorrhizal fungi; RM1: recovery medium 1; RM2: recovery medium 2; Tul1: tulasnella isolate 1; Tul2: tulasnella isolate 2.
\end{abstract}

\section{Authors' contributions}

ES and EPJ carried out the cryopreservation experiments, ES analysed the data. ES and VS wrote the article; VS conceived the idea and designed the project. All authors read and approved the final manuscript.

\section{Acknowledgements}

We kindly acknowledge Jonathan Kendon and Kazutomo Yokoya for collecting and storing the orchid seed, and culturing the orchid mycorrhizal isolates used in this study. We also thank Rui Fang for assisting data analysis.

\section{Competing interests}

The authors declare that they have no competing interests.

An explanation of why your manuscript should be published in Botanical Studies

This manuscript explains the benefits of using simple cryopreservation method for storing orchid seeds, avoiding the need for vitrification, for endemic taxa covering epiphytic, lithophytic and terrestrial life forms from one of the most biodiverse areas of the world for orchids. Use of symbiotic recovery system as a potential tool is discussed for species of Angraecum and Benthamia (two large genera with more than 160 species in total), which can be tested for large number of species from both these genera. The methods described in the paper can be used as standard protocols for large scale ex situ conservation projects in Madagascar and other areas of the world where orchid species are facing biodiversity decline.
An explanation of any issues relating to journal policies Not applicable.

\section{Availability of data and materials}

The authors confirm that local, national and international guidelines and legislation are followed by acquiring appropriate permissions and licences for the study.

Confirmation that all authors have approved the manuscript for submission

All authors have approved the manuscript for submission to Botanical Studies.

Confirmation that the content of the manuscript has not been published, or submitted for publication elsewhere

The whole or part of the manuscript has not been published or under consideration for publication anywhere else.

\section{Ethics approval and consent to participate}

Not applicable.

\section{Funding}

We acknowledge the financial support received from the Sainsbury Orchid Endowment.

\section{Publisher's Note}

Springer Nature remains neutral with regard to jurisdictional claims in published maps and institutional affiliations.

Received: 6 December 2017 Accepted: 2 May 2018

Published online: 09 May 2018

\section{References}

Bailarote BC, Lievens B, Jacquemyn H (2012) Does mycorrhizal specificity affect orchid decline and rarity? Am J Bot 99:1655-1665. https://doi. org/10.3732/ajb.1200117

Batty AL, Dixon KW, Brundrett M, Sivasithamparam K (2001) Constraints to symbiotic germination of terrestrial orchid seed in a mediterranean bushland. New Phytol 152:511-520. https://doi. org/10.1046/j.0028-646X.2001.00277

Clements M (1988) Orchid mycorrhizal associations. Lindleyana 3:73-86

Cribb P, Hermans J (2009) Field guide to the orchids of Madagascar orchids. R Bot Gard, Kew

Dutra D, Johnson TR, Kauth PJ et al (2008) Asymbiotic seed germination, in vitro seedling development, and greenhouse acclimatization of the threatened terrestrial orchid Bletia purpurea. Plant Cell Tissue Organ Cult 94:11-21. https://doi.org/10.1007/s11240-008-9382-0

Ercole E, Rodda M, Molinatti M et al (2013) Cryopreservation of orchid mycorrhizal fungi: a tool for the conservation of endangered species. J Microbiol Methods 93:134-137. https://doi.org/10.1016/j.mimet.2013.03.003

Galdiano RF, de Macedo Lemos EG, de Faria RT, Vendrame WA (2014) Seedling Development and evaluation of genetic stability of cryopreserved Dendrobium hybrid mature seeds. Appl Biochem Biotechnol 172:2521-2529. https://doi.org/10.1007/s12010-013-0699-8

Hu WH, Yang YH, Liaw SI, Chang C (2013) Cryopreservation the seeds of a Taiwanese terrestrial orchid, Bletilla formosana (Hayata) Schltr. by vitrification. Bot Stud. 54:33. https://doi.org/10.1186/1999-3110-54-33

Jitsopakul N, Thammasiri K, Ishikawa K (2008) Cryopreservation of Bletilla striata mature seeds, 3-day germinating seeds and protocorms by dropletvitrification. CryoLetters. 29:517-526

Jitsopakul N, Thammasiri K, Yukawa T, Ishikawa K (2012) Effect of cryopreservation on seed germination and protocorm development of Vanda tricolor. ScienceAsia 38:244. https://doi.org/10.2306/ scienceasia1513-1874.2012.38.244

Johnson TR, Stewart SL, Dutra D et al (2007) Asymbiotic and symbiotic seed germination of Eulophia alta (Orchidaceae)_-preliminary evidence for the symbiotic culture advantage. Plant Cell Tissue Organ Cult 90:313-323. https://doi.org/10.1007/s11240-007-9270-z 
Kulus D, Zalewska M (2014) Cryopreservation as a tool used in long-term storage of ornamental species-a review. Sci Hort 168:88-107

Li DZ, Pritchard HW (2009) The science and economics of ex situ plant conservation. Trends Plant Sci 14:614-621

Merritt DJ, Hay FR, Swarts ND et al (2014) Ex situ conservation and cryopreservation of orchid germplasm. Int J Plant Sci 175:46-58. https://doi. org/10.1086/673370

Miyoshi K, Mii M (1995) Phytohormone pre-treatment for the enhancement of seed germination and protocorm formation by the terrestrial orchid, Calanthe discolor (Orchidaceae), in asymbiotic culture. Sci Hortic (Amsterdam) 63:263-267. https://doi.org/10.1016/0304-4238(95)00813-9

Nikishina TV, Popov AS, Kolomeitseva GL, Golovkin BN (2001) Cryopreservation of seeds of some tropical orchids. Dokl Biochem Biophys 378:231-233. https://doi.org/10.1023/A:1011585801668

Nishizawa S, Sakai A, Amano Y, Matsuzawa T (1993) Cryopreservation of asparagus (Asparagus officinalis L.) embryogenic suspension cells and subsequent plant regeneration by vitrification. Plant Sci 91:67-73

Popova EV, Nikishina TV, Kolomeitseva GL, Popov AS (2003) The effect of seed cryopreservation on the development of protocorms by the hybrid orchid Bratonia. Russ J Plant Physiol 50:672-677. https://doi.org/10.102 3/A:1025600526588

Popova E, Kim HH, Saxena PK et al (2016) Frozen beauty: the cryobiotechnology of orchid diversity. Biotechnol Adv 34:380-403. https://doi. org/10.1016/j.biotechadv.2016.01.001

Rafter M, Yokoya K, Schofield EJ et al (2016) Non-specific symbiotic germination of Cynorkis purpurea (Thouars) Kraezl., a habitat-specific terrestrial orchid from the Central Highlands of Madagascar. Mycorrhiza 26:541552. https://doi.org/10.1007/s00572-016-0691-6

Ramiadantsoa T, Ovaskainen O, Rybicki J, Hanski I (2015) Large-scale habitat corridors for biodiversity conservation: a forest corridor in Madagascar. PLoS ONE 10:e0132126. https://doi.org/10.1371/journal.pone.0132126

Sakai A, Engelmann F (2007) Vitrification, encapsulation-vitrification and droplet-vitrification: a review. Cryo-Letters 28:151-172
Sakai A, Kobayashi S, Oiyama I (1990) Cryopreservation of nucellar cells of navel orange (Citrus sinensis Osb. var. brasiliensis Tanaka) by vitrification. Plant Cell Rep 9:30-33. https://doi.org/10.1007/BF00232130

Seaton PT, Hu H, Perner H, Pritchard HW (2010) Ex situ conservation of orchids in a warming world. Bot Rev 76:193-203. https://doi.org/10.1007/ s12229-010-9048-6

Sommerville KD, Siemon JP, Wood CB, Offord CA (2008) Simultaneous encapsulation of seed and mycorrhizal fungi for long-term storage and propagation of terrestrial orchids. Aust J Bot 56:609. https://doi.org/10.1071/ BT08008

Sopalun K, Thammasiri K, Ishikawa K (2010) Vitrification-based cryopreservation of Grammatophyllum speciosum protocorms. Cryo-Letters 31:347-357

Swarts ND, Dixon KW (2009) Terrestrial orchid conservation in the age of extinction. Ann Bot 104:543-556. https://doi.org/10.1093/aob/mcp025

Teixeira da Silva JA, Zeng S, Galdiano RF et al (2014) In vitro conservation of Dendrobium germplasm. Plant Cell Rep 33:1413-1423

Vendrame W, Faria RT, Sorace M, Sahyun SA (2014) Orchid cryopreservation. Ciência e Agrotecnologia 38:213-229. https://doi.org/10.1590/ S1413-70542014000300001

Wood CB, Pritchard HW, Miller AP (2000) Simultaneous preservation of orchid seed and its fungal symbiont using encapsulation-dehydration is dependent on moisture content and storage temperature. Cryo-Letters 21:125-136

Yamazaki J, Miyoshi K (2006) In vitro asymbiotic germination of immature seed and formation of protocorm by Cephalanthera falcata (Orchidaceae). Ann Bot 98:1197-1206. https://doi.org/10.1093/aob/mcl223

Yokoya K, Zettler LW, Kendon JP et al (2015) Preliminary findings on identification of mycorrhizal fungi from diverse orchids in the Central Highlands of Madagascar. Mycorrhiza 25:611-625. https://doi.org/10.1007/ s00572-015-0635-6

Zotz G (2013) The systematic distribution of vascular epiphytes - a critical update. Bot J Linn Soc 171:453-481. https://doi.org/10.1111/boj.12010

\section{Submit your manuscript to a SpringerOpen ${ }^{\circ}$ journal and benefit from:}

- Convenient online submission

- Rigorous peer review

- Open access: articles freely available online

- High visibility within the field

- Retaining the copyright to your article

Submit your next manuscript at $\boldsymbol{\nabla}$ springeropen.com 